\title{
Employee and Organisational Performance: Employees Perception of Intrinsic and Extrinsic Rewards System
}

\author{
Noko Emmanuel ${ }^{1, *, \dagger}$ and Nwuzor Joseph ${ }^{2, \dagger}$ \\ ${ }^{1}$ Northumbria University, London and ${ }^{2}$ Boston University, Massachusetts \\ *corresponding author: emmanuelnoko@yahoo.com \\ ${ }^{\dagger}$ Auhtors Contributed equally.
}

\begin{abstract}
Background: The study aimed to evaluate the perception of employees on both intrinsic and extrinsic reward system and whether reward system impact their performance and the organization performance at large. Method: To achieve the objective, the study employed Structural Equation Modelling (PLS-SEM) approach to test six hypothesis. The study sampled 400 employee of Zenith Bank Plc using questionnaire send to the respondent emails. Findings: PLS-SEM result revealed that both extrinsic and intrinsic rewards have positive and significant impact on employee performance, although, extrinsic appear more potent than intrinsic rewards. It was further revealed that three of the four measure of employee performance; quality job, effective service delivery, customer rating has positive significant with organization performance while time management was unable to explain organization performance. We discovered also that gender does not play any significant role on employee performance, but age does. Conclusion: The study therefore concluded that rewards play an important role in both employee performance and organization performance.
\end{abstract}

Key words: Employee performance; Extrinsic rewards; Intrinsic Rewards; Organization performance; PLS- SEM; Rewards System.

\section{Introduction}

The dynamics of today's business environment is so intense that organization are constantly in search of ways to remain competitive and provide unmatched customer focused products and services. This is even more important given that organization customers (internal and external) have lots demanding their attention, customers therefore give more priorities to those firms who can provide the best of services and product through innovative process at a less cost and resources (Nisar et al.; 2014). To remain innovative and creative in meeting the unending customer needs the internal customers needs to be motivated to gives their best.
Murphy (2015)agrees that the most valuable assets in an organisation are the people working in it, interestingly because of human nature, people are also the most difficult resource to handle. This is so because humans have their own individual needs that must be met and their set of peculiar habits that must be managed if they are to play a contributory role in achieving the twin organisational goals of growth and development (Osabiya; 2015).

Similarly, Khan et al. (2014) have stressed that effective reward system has been one successful strategy employed top organization to make employees more satisfied, induce their creative ability and quick responsiveness to customer needs. The satisfaction of employees depends on their thinking, perception, and feelings towards job because in a highly workload situation that often arise in every organization 
requires extra efforts of the employees satisfactorily. This requires an effective and efficient contribution of employees to perform and play a vital role in growth and development of organization (Khan et al.; 2014). Therefore, to maintain a healthy and workable environment in high workload situation it is critical to develop a competitive reward system that encompass both intrinsic and extrinsic motivational tools.

Reward systems have always been an integral aspect of the management process albeit in different forms and for most of history practiced with no formalization or explicit rules (Guest; 2017). The emergence and popularization of various motivation theories led to the adoption of intentionally designed reward systems to spur employees towards high performance. According to Yapa (2002), employee rewards can be conceptualized as motivation packages that are 'designed to attract and retain skilful workforce with the intention of achieving competitive advantage'. The logic behind the use of employee rewards as motivational tools is that such rewards would increase the satisfaction levels of employees and thus improve their performance. Bratton and Gold (2003) also noted that rewards are major tools for achieving the maximization of employee performance and they comprise all forms of tangible and intangible returns or benefits which an employee enjoys as part of a defined employer- employee relationship.

There are two broad categorizations of rewards used by organizations in bringing about high employee performance: intrinsic and extrinsic rewards. Samnani and Singh (2014) expressed those intrinsic rewards are an integral part of the job and are also referred to as psychic rewards because they are self- generated and experienced directly by an employee. On the other hand, extrinsic rewards are external to the job and are usually of a financial or tangible nature (Mahaney and Lederer; 2006). Examples of intrinsic rewards include recognition, responsibility, career advancement and learning opportunity, extrinsic rewards include pay, bonus, benefits, promotions, and allowances. Organizations utilize various degrees of the combination of intrinsic and extrinsic rewards in motivating employees and thus spurring them to higher performance.

Ever since the use of increased pay to bring about higher productivity by the Ford Motor Company in the early part of the twentieth century, a link has been established between the level of employee satisfaction and performance (Greenspan; 2005). C. and Abiola (2004) and Armstrong et al. (2011) have expressed the view that sustained high performance by an employee or group of employees can only result when there are acceptable levels of needs satisfaction. Ensuring satisfaction of employees has been achieved repeatedly using a wide array of carefully designed reward systems. According to Yapa (2002), 'an important milestone in the human resource management movement is the recognition of the fact that rewards do matter, and they do shape human performance in a wide range of situation'. Various contemporary organisations have used an array of systems combining bonus, comfortable work conditions, promotions, learning opportunity and recognition among others to achieve improvements in employee productivity and job accomplishment as dimensions of performance.

For organization operating in the service industry, effective rewards system of great importance to them given that the industry is very competitive with loads of multinational firms entering the market and customers have little patients for poor service delivery (Osabiya; 2015). Since business survival hinges on employee performance, it is therefore a viable and sensible strategy for a company seeking to remain competitive in their industry to ensure that conditions are created which foster top employee performance. However, as reported by Samnani and Singh (2014), Onashile (2017), getting organizations to make a practical decision that will keep and retain top performing employees is a herculean task in the face of dearth of empirical evidence that rewards systems indeed have effects on employee performance. A major problem in linking rewards systems with employee performance lie in the difficulty of providing metric measurements of the variables of intrinsic and extrinsic rewards and employee performance.

A definite consensus is also lacking in the field because of other extraneous variables that might impinge on the relationship between rewards and employee performance. Such extraneous variables include the fact that corporate cculture cannot be wholly generalized and essentially differ from one organization to the other. Nevertheless, justifying corporate decisions on the design and implementation of reward systems rely on objective portrayal of the relationship between the components of the two variables. While literature exists on motivation and employee performance, there has been growing debates about the approach adopted in literature in quantifying motivation whether intrinsic or extrinsic rewards (C. and Abiola; 2004; Osabiya; 2015; Onashile; 2017). Similarly, the manager is always interested in understanding which is more effective in motivating the different class of employees in the organization, particularly as recent literature suggest that employees differs in what motivates them.

The study therefore seeks to establish a positive link between rewards system (intrinsic and extrinsic rewards) and employee performance. The rest of the paper is organized into a literature review, methodology, analysis and discussion, and a conclusion. The literature review provides a systematic review of other literature focusing on theories and empirical studies while the methodology discusses the process of generating and analysing the data. The analysis and discussion section present and discuss the result from the survey and the last section draw conclusion from the result and discussion and provide policy implication of the study.

\section{Literature Review}

\subsection{Motivation and Rewards}

Rewards differs in nature and can be grouped into different categories depending on the objectives in question. According to Bratton and Gold (2003), 'reward can be defined as the cash, non- cash, and psychological payments provided to an employee by an organization in return for the services rendered by the individual'. Nnaji-Ihedinmah and Egbunike (2015) defined rewards as the aggregate of benefits that employees receive from their employer, and which are considered as the determinants of job satisfaction and commitment. This definition is like the one provided by Malhotra et al. (2007) as it stressed the fact that rewards have a demonstrable link with job satisfaction. An important dimension of the function of reward is included in the definition of Bratton and Gold (2003), according to the author, 'rewards are major tools for achieving the maximization of employee performance and they comprise all forms of tangible and intangible returns or benefits which an employee enjoys as part of a defined employer- employee relationship'. Fay and Thompson (2001) pressed the view that rewards are why people work and can be defined as the various ways in which an organization meets the needs of employees so that such employees perceive that their livelihood are linked to the performance of their duties 
to the organization.

For Gerhart and Fang (2004), reward can be viewed as consisting of three components which are compensation, benefits, and careers. Each of these components also have different sub- components which are more easily integrated into reward measurement systems. The sub- components of compensation include salaries, base- pay, bonuses and other short- and long-term incentives. Health benefits, insurance coverage and work- life balance are the sub- components of benefits while career progression rates and training and development are the components of careers. The various rewards used in an organization are often dispensed through reward systems. Reward systems refer to intentionally designed programs which organizations use to reward performance and motivate employees either on an individual or a group basis (Nnaji-Ihedinmah and Egbunike; 2015). Reward systems can also be conceptualized as the collection of organizational components of processes, rules, procedures, people and decisionmaking activities that are utilized in the systematic allocation of compensation and benefits to employees in exchange for their services and contribution (Puwanenthiren; 2011)).

The design and implementation of reward systems entail an organization specifying its goals or objectives to be achieved over a specific time frame, the specific behaviors or actions that are congruent with such goals, and most importantly the level of performance that will attract rewards (Puwanenthiren; 2011). Rewards is generally a motivational tool employed by the organization to motivates its employees to higher productivity. Raya (2015) define motivation as a driving force that makes an individual act in a specific way. The psychological rationale or bulwark in an employee that serves to mitigate the manifestation or expression of the negative dynamics of frustration, regression, fixation or withdrawal in that particular employee. This is particularly relevant in a service delivery sector where the customers demand a high level of service from service providers regardless of the various constraints on the system.

\section{2 Intrinsic and extrinsic Rewards}

A common thread across literature is the categorization of rewards into intrinsic and extrinsic. This classification pervades the study of rewards systems across seemingly disparate domains (Hatice; 2012; Osibanjo et al.; 2014). Intrinsic rewards are characterized as those rewards that are self- generated, psychic, experienced directly by an employee and forming an internal part of the job (Samnani and Singh; 2014). Intrinsic rewards are further described by Yapa (2002) as derivable from the content of a specific job function or work task. By nature, intrinsic rewards are inherent in the job itself and tend to be subjective, depending on the perception of the employee. Examples of intrinsic rewards include recognition, responsibility, career advancement and learning opportunity, variety, creativity, self- direction, responsibility, feedback and the opportunities to use one's abilities or skills.

According to Mahaney and Lederer (2006), extrinsic rewards comprise the tangible rewards and benefits associated with a particular activity. Most times they are of a financial nature and have an element of objective measurement. Examples of extrinsic rewards include bonuses, promotions, corner offices, paid vacation trips, time off, high salaries. Nnaji-Ihedinmah and Egbunike (2015) mentioned that some organizations offer flexible benefits plan without the management making a choice for employees. The authors reported that 'under the benefits plan employees are allowed to choose from varying options of banking time- off, gains sharing and skills- based pay'. Asides from the availability of external rewards, the use of choice provides a level of engagement that have also been shown to improve employee performance (Samnani and Singh; 2014).

While both intrinsic and extrinsic rewards are important to keeping employees satisfied and positioning them for higher performance, it is important to point out that care must be taken in the design of reward systems because individuals or groups respond differently to various combinations of intrinsic and extrinsic rewards. Mahaney and Lederer (2006) suggested that the design of reward systems should be based on the careful evaluation of information on what the employees perceive as valuable, the cultural context in which the employees work and the resources available to run such reward systems. The aforementioned factors are important in the design of reward systems because of the need to guarantee the efficiency and effectiveness of such systems. While some organizations or professions naturally veer towards the use of intrinsic rewards, the design and implementation of rewards systems with more extrinsic components is common in the commercial sector.

Osibanjo et al. (2014) relayed that organisation with reward programs in which employees can choose the kind of reward package they want have consistently shown higher performance. In the design of reward systems, it is important to note that the intrinsic- extrinsic reward dichotomy is a recent one and is based on the Herzberg theory of motivation who noted that rewards can be divided into those which are related to the content of the work and thus termed intrinsic and those which are external to the work and thus termed extrinsic. Herzberg called the intrinsic rewards motivators and he expressed that in their absence, there can be no satisfaction, as such he held intrinsic rewards to be more important than extrinsic rewards.

\subsubsection{Measuring Employee Performance: Models and difficulties}

The constantly changing dynamics of the business environment have necessitated the interest in performance measurement and management by many organizations. Samnani and Singh (2014) maintained that the main role of performance measurement is to assess the current position of the organization and help managers implement and create strategy. The different models of measuring performance include the balanced scorecard model, the Malcolm Baldridge model, Performance Prism and the European Foundation for Quality Management model (Onashile; 2017).

Armstrong (2009) suggested that employee performance should be encompassing of the different dimensions of strategy, processes, leadership and competencies. This is in response to the conventional modes of measuring performance which is often based on the dimension of competencies. Informally, employee performance is deemed as reflected in the organizational performance level. Formally, employee performance levels are measured using performance appraisals. Onashile (2017) asserted that performance appraisal policies reflect an evolution towards more formalized systems of measuring performance based on the specialization of functions that have come to characterize the corporate environment. Another difficulty lies in the often-cited ratter's bias which applies to managers rating a particular employee. Key popular metric used in measuring the informal employee performance includes Quality of job delivery, timely delivery of task, effective time management, and customer rating. 


\subsection{Theoretical Foundation}

An important theoretical framework applicable to this study is the Vroom's expectancy theory. Propounded in 1964 by Victor Vroom, the theory is built on the concept of expectancy. According to Vroom (1964), 'expectancy is the momentary belief concerning the likelihood that a particular act will be followed by a particular outcome'. The theory expresses that for employees to perform any act or comply with a specified behavior, two factors are important: the expectancy and the perceived value of the outcome or valence. The expectancy theory asserts that rewards and performance work through a path- goal mechanism that underlie employees taking only those actions they feel would result in their obtaining rewards they consider worthwhile.

Ryan and Pointan (2005) suggested that the crux of the Vroom's expectancy theory is the realization that employees will make certain behaviors their choice if they believe that the pay- off from such behaviour will be more than the costs. C. and Abiola (2004) asserted that three factors determine the choice of behaviour among employees: valence, instrumentality, and expectancy. For Gerhart and Fang (2004), the main application of Vroom's expectancy theory is that the management of an organization should instil into employees the expectation that their actions have consequences. Secondly, management should be consistent in the application of rewards to identified actions. The strength of the model and its applicability to this study is its predictive nature which holds through under most circumstances.

\subsection{Rewards system and Employee Performance}

Various studies have reported the link between rewards' systems and employees' performance in several different settings. The most conventional linkage is that effective rewards systems guarantee high employee satisfaction which in turn spur employees towards higher performance. Thomas (2008) reported that adequate intrinsic rewards have been shown to improve the performance levels of employees in their studies. According to the authors, the activities of accomplishing set targets, volunteering for challenging assignments, taking up management and leadership responsibilities and the pursuit of professional growth are intrinsic rewards that improve employee satisfaction and consequently on the job performance. A significant link between rewards' system and performance is the simple realization that employees do not work for free. This was emphasized by Gerhart and Fang (2015) when they argued that for employees to perform, they need to be motivated. The need for motivation in today's business environment have necessitated the need for an intentionally designed reward system.

Thomas (2009) was more specific in tracing the cause-andeffect relationship between rewards and performance. For the author, intrinsic rewards have certain psychological benefits, a sense of choice, a sense of meaningfulness, a sense of competence and a sense of progress. A sense of choice results when employees use their judgement and experience in choosing the strategies and tactics required for the performance of their job tasks. When such strategies and tactics yield results, employees are satisfied and tend towards higher performance. Also, the perception that their initiatives are leading to excellent work results have been shown to lead to higher performance among employees. This basic mechanism applies to the components of meaningfulness and progress and lead to a feedback cycle that transforms these intrinsic rewards into high perfor- mance (Gerhart and Fang; 2015).

The use of tangible benefits as the main form of reward systems have been identified as one of the fastest ways to improve performance levels among employees. According to Qureshi et al. (2013), 'the conventional view among managers is that tying pay to job performance is essential to improving productivity'. The authors further asserted that a company can reliably build a high-performance work environment using flexibility benefits, paid time- off, profit sharing and skill- based pay. The findings of this study have been corroborated by those of Osibanjo et al. (2014) who noted that organisations that have introduced gain- sharing plans for employees have recorded a boost in productivity. The authors further reported that when employees are allowed to make their choices from several compensation packages or plans, the improvement in productivity is even higher. Many researchers have found that employees' job satisfaction is affected by both financial and non-financial rewards (Gerald and Dorothy; 2004; Rehman et al.; 2010). An ineffective reward management will affect employees' satisfaction and de-motivate them, hence affecting their performance outcome. Rewards is one of the important elements to motivate employees for contributing their best effort to generate innovation ideas that lead to better business functionality and further improvise company performance both financial and nonfinancially.

\section{Research Methodology}

This study employed a descriptive survey design and adopted a quantitative research approach using questionnaire design and distributed to the employees of Zenith Bank Plc. The authors used Microsoft online form tools to send the survey link to the employees either through their email or WhatsApp. The link was sent to all Zenith Bank staffs within the rich of the researcher and the researcher set sample size to 400 , such that immediately 400 responses are received the link was no longer working and anyone who sent response after then could be received by the researcher. The link contains an introductory letter inviting the staffs to participate in the survey and respondents ere asked to share the link with their colleagues only (Cao et al.; 2019). Lastly, following the suggestion of Cao et al. (2019), the study also conducted correlation test among the latent variables and our result as seen in table 2 reveals that there is no evidence of high correlation suggesting that common bias is also unlikely. Lastly, all the construct items were derived from existing peer review literature and the constructs were measured using five-point Likert scales ranging from 'totally disagree' (1) to 'totally agree' (5).

\section{Analysis and Discussion}

Table 1 present the demographic information of the participants and as can be seen the participants are well informed and gender balanced. The measurement model for the reflective constructs in our model is examined in terms of construct validity of the measurement scales, indicator reliability, convergent, and discriminant validity. The internal consistency of each construct was also well above the recommended threshold of 0.7 (Hair et al.; 2016). The reliability test of Cronbach's alpha (CA) that explains the relationship of latent variables and the manifest indicators conform to the verdict of above 0.7 (Cao et al.; 2019).

All loadings as seen in Table 2 were above this recommended threshold. To establish convergent validity, we 


\begin{tabular}{l|l|l|l}
\hline Demography Variable & Classification & Frequency & Percentage\% \\
\hline Age & $<25$ & 128 & 32.0 \\
& $25-35$ & 164 & 41.0 \\
& $36-45$ & 98 & 24.5 \\
Gender & $56-65$ & 10 & 2.5 \\
\multirow{5}{*}{ Education } & 66 and above & 0 & 0.0 \\
& Male & 206 & 51.5 \\
& Female & 194 & 48.5 \\
& High School & 36 & 9.0 \\
& Bachelor Degree & 214 & 53.5 \\
& Master Degree & 146 & 36.5 \\
& PhD & 3 & 0.75 \\
& Others & 1 & 0.0 \\
\hline
\end{tabular}

Table 1. Demography overview

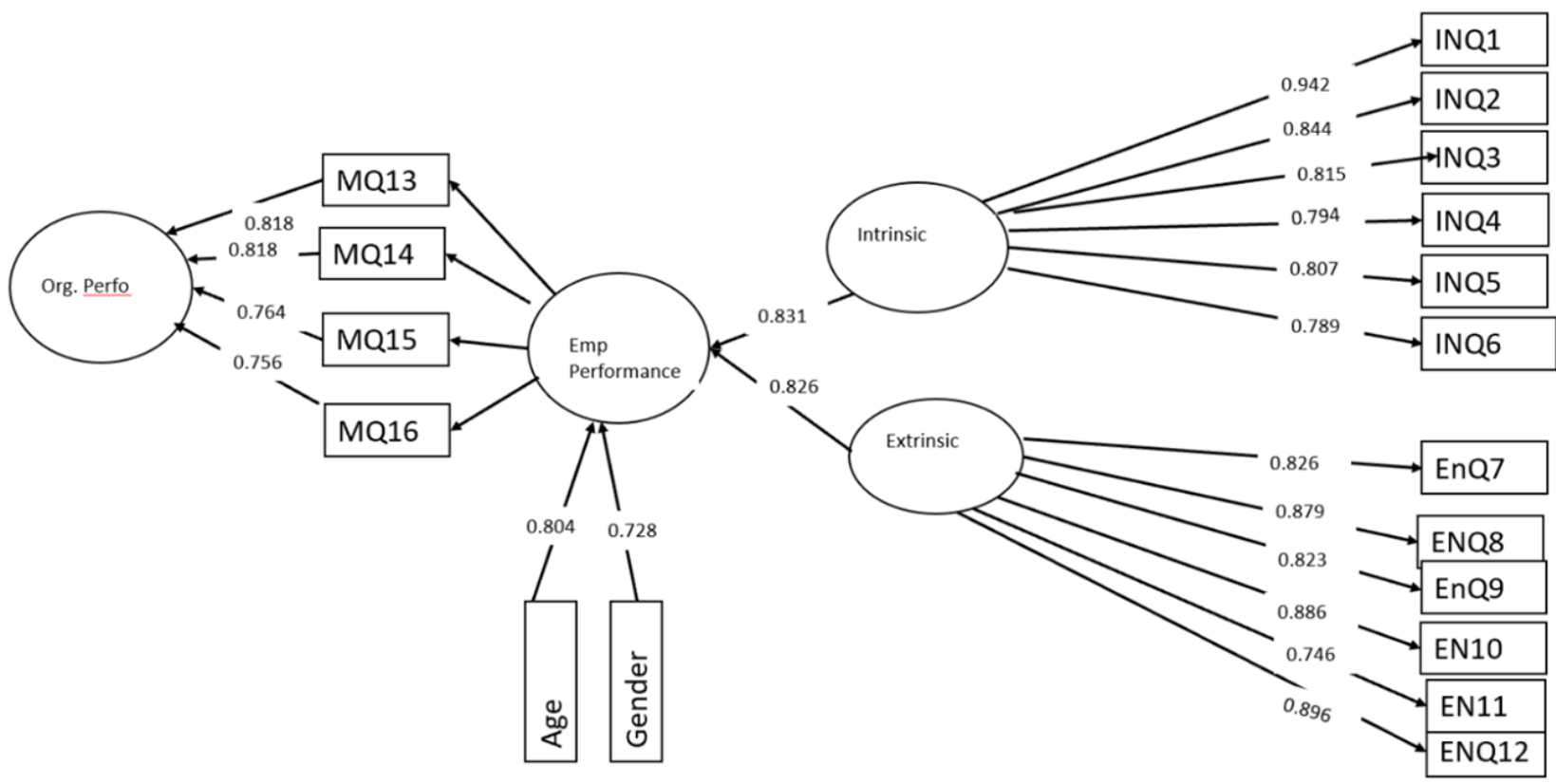

Figure 1. Structural Equation Model Path

Table 2. The measurement model Factor Loading and Descriptive Mean

\begin{tabular}{|c|c|c|c|c|c|}
\hline Measurement & Factor Loading & Mean (SD) & Cronbach's alpha (CA) & Construct Validity & Average Variance (AVE) \\
\hline Extrinsic Motivation & & & 0.856 & 0.903 & 0.694 \\
\hline High Salary & 0.942 & $4.31(0.95)$ & & & \\
\hline Salary Increment & 0.844 & $4.52(0.55)$ & & & \\
\hline Bonus/allowance & 0.815 & $4.06(072)$ & & & \\
\hline Paid vacation & 0.794 & $4.02(0.92)$ & & & \\
\hline Scholarship Benefits & 0.807 & $4.14(1.07)$ & & & \\
\hline Tax rebatement & 0.789 & $3.82(0.92)$ & & & \\
\hline Gift Card & 0.732 & $3.84(1.20)$ & & & \\
\hline Intrinsic Motivation & & & 0.842 & 0.887 & 0.726 \\
\hline Increased responsibility & 0.826 & $4.02(0.89)$ & & & \\
\hline Career advancement & 0.896 & $4.26(079)$ & & & \\
\hline Recognition & 0.823 & $4.18(0.96)$ & & & \\
\hline Learning opportunities & 0.786 & $4.04(1.07)$ & & & \\
\hline Citations/ Recommendations & 0.746 & $3.84(0.93)$ & & & \\
\hline Inclusion in committees & 0.896 & $3.96(0.79)$ & & & \\
\hline
\end{tabular}

Source: Authors

examined the Average Variance Extracted (AVE). The AVE measures the amount of variance captured by the focal construct from its indicators relative to the measurement error. MacKenzie et al. (2011) point out that AVE should be greater than 0.5 to ensure constructs account for more than $50 \%$ of the variance in its indicators. As can be inferred from 
Table 3. Latent Variables Correlation Matrix

\begin{tabular}{lllll}
\hline & Extrinsic & Intrinsic & Emp. Performance & Org. Performance \\
\hline Extrinsic & 0.9124 & & & \\
Intrinsic & 0.418 & 0.829 & & \\
Emp. Performance & 0.394 & 0.413 & 0.797 & \\
Org. Performance & 0.457 & 0.420 & 0.493 & 0.849 \\
\hline
\end{tabular}

Source: Authors.

Table 2, the reported AVE values of the constructs met this criterion.

Finally, we examined the discriminant validity of our measurement model. It represents the extent to which each of the constructs in our model differ from each other. To assess whether discriminant validity between the constructs in our model had been established, we used Heterotrait-Monotrait (HTMT) ratio of correlations as presented in table 3.

\subsection{Structural Equation Model}

To examine the structural equation model, we use both the level of significance of the path coefficients and the variance explained (R2), a measure of the variance explained by the independent variables (Hair et al.; 2016). Both the path coefficient and the R-square is used to judge the model performance in predicting the assumed relationship. Figure 1 capture the hypothesized structural model relationship while Table 4 present the paths and the level of significance. As expected, most of the construct have significant positive effect on motivation.

Following the bootstrapping procedure using 5000 resamples and the statistical significance of the path coefficients were determined using a two-tailed distribution (Hair et al.; 2016). In total, the results indicate that five out of six hypotheses tested in the model were significant. For instance, intrinsic motivation on employee performance $(\beta=-0.214, \rho=0.001)$, extrinsic motivation $(\beta=0.185, \rho=0.000)$, etc. However, contrary to initial predictions, the study found no empirical evidence for the direct effect of employee performance in the form of quality time management impacting the organisational performance $(\beta=0.386, \rho=0.128)$.

Our finding is consistent with literature on rewards and employee performance. As seen in the model, intrinsic and extrinsic motivational tools both has significant impact on employee performance. Similarly, we argued from theoretical background as in Figure 1 that improved employee performance can be manifested in four dimension, quality job delivery, high customer rating, effective delivery, and time management.

We measured whether these four dimensions impacts the performance of the organization, and it was revealed that three of the four dimensions (quality job, effective delivery, and customer rating have positive impact on organization performance while time management does not have any impact contrary to literature. The study is consistent with earlier literature on rewards and employee performance (Samnani and Singh; 2014; Hatice; 2012). However, some empirical studies assert the ineffectiveness intrinsic rewards in motivating employee.

\section{Conclusion}

The study investigated the impact of reward system as a motivational tool on employee performance using structural equation modelling. A large percentage of polled managers asserted that extrinsic rewards such as high salary, salary increments, and bonuses influence performance to a greater extent. Other extrinsic rewards such as paid vacation, benefits and gifts are significant. Extrinsic rewards in an organisation have the characteristics of being easily measurable, justifiable, and embedded in organisational routines and processes.

The importance attached to extrinsic rewards have been reported in other studies and provided evidence corroborating the findings of this study. Studies like Nnaji-Ihedinmah and Egbunike (2015) and Murphy (2015) suggested that extrinsic rewards are perceived as more effective even by employees. Murphy (2015) further expressed that this importance is greater in professions where employees are exposed to safety risks and occupational hazards.

Similarly, it was revealed also that career advancement, recognition, learning opportunities, and increased responsibility are significant as intrinsic rewards tools used to motivate employees affirming the findings of (Kumar; 2014). Also, we find that age plays role on employee performance while gender does not make any significant difference.

One of the most basic conventional views of management is that individual motives for actions are based on a number of needs including psychological, safety, esteem, belonging and self- actualization. Meeting these needs is the basis for spurring employees towards higher performance and is achieved through a combination of monetary and non- monetary benefits. As such both intrinsic and extrinsic rewards are important in motivation. The onus is therefore on managers to create a balance in the use of intrinsic and extrinsic rewards.

The implication of the study is that managers alike should pay close attention to their reward system in not only retaining the best talent but driving the innovative ability that will keep them ahead of competitors.

\section{Competing Interests}

Authors declare no competing interest.

\section{References}

Armstrong, M. (2009). A handbook of human resources management practice, 10th ed edn, London: Kogan Page.

Armstrong, M., Brown, B. and Reilly, T. (2011). Increasing the effectiveness of reward management: An incentive based approach, Human Relations 33(1): 106-20.

Bratton, J. and Gold, J. (2003). Human Resources Management: Theory and practice, 3rd ed edn, New York: Palgrave- MacMillan. 
Table 4. Result of Structural Path

\begin{tabular}{llllll}
\hline Hypothesis & Path Coefficient & Beta & T-test & Remark & P-value $(5 \%)$ \\
\hline H1 & Intrinsic - > Emp. performance & 0.214 & 3.814 & Significant & 0.001 \\
H2 & Extrinsic - > Emp. performance & 0.185 & 3.245 & Significant & 0.000 \\
H2a & Emp. performance $*$ QualityJob $->$ Org. Performance & 0.703 & 8.520 & Significant & 0.000 \\
H2b & Emp. performance $*$ Effectivedelivery- $>$ Org. Performance & 0.529 & 6.322 & Significant & 0.000 \\
H2c & Emp. performance $*$ customerrating - > Org. Performance & 0.647 & 5.145 & Significant & 0.000 \\
H2d & Emp. performance $*$ timemgt- $>$ Org. Performance & 0.386 & 1.216 & Not Sig. & 0.128 \\
& Age - > emp performance & 0.340 & 2.425 & Significant & 0.042 \\
& Gender $->$ emp performance & 0.032 & 1.684 & Not sig. & 0.092 \\
\hline
\end{tabular}

Source: Authors

C., A. and Abiola, A. (2004). Influence of rewards on work performance in an organization, Journal of Social Sciences 8(1): 712.

Cao, X., Khan, A. N., Ali, A. and Khan, N. A. (2019). Consequences of cyberbullying and social overload while using snss: A study of users' discontinuous usage behavior in snss, Information Systems Frontiers 3(1): 1-14.

Fay, C. H. and Thompson, M. A. (2001). Contextual determinants of reward's system success: An exploratory study, $\mathrm{Hu}^{-}$ man Resources Management 40(3): 213-226.

Gerald, K. and Dorothy, K. (2004). Rewarding success and failure: Performance incentives use, Personnel Review 26(3): 187-200.

Gerhart, B. and Fang, M. (2004). Creating an effective total reward strategy: Holistic approach better supports business success, Benefits Quarterly 20(3): 7-12.

Gerhart, B. and Fang, M. (2015). Pay, intrinsic motivation, extrinsic motivation, performance, and creativity in the workplace: Revisiting long-held beliefs, Annu. Rev. Organ. Psychol. Organ. Behav 2(1): 489-521.

Greenspan, A. (2005). The age of turbulence, 2nd ed edn, New York: Penguin.

Guest, D. (2017). Human resource management and employee well-being: Towards a new analytic framework, Human Resource Management Journal 27(1): 22-38.

Hair, J. F., Hult, G. T., Ringle, C. and Sarstedt, M. (2016). A primer on partial least squares structural equation modeling (PLSSEM), Thousand Oaks: Sage Publications.

Hatice, O. (2012). The influence of intrinsic and extrinsic rewards on employee results: An empirical analysis in turkish manufacturing industry, Business and Economic Research Journal 23(3): 29-48.

Khan, F., Yusoff, R. and Khan, A. (2014). Job demands, burnout and resources in teaching a conceptual review, World Applied Sciences Journal 30(1): 20-28.

Kumar, R. (2014). The challenges to the implementation of lean manufacturing., International Journal of Engineering Science, Advanced Technology 4(4): 307-312.

MacKenzie, S. B., Podsakoff, P. M. and Podsakoff, N. P. (2011). Construct measurement and validation procedures in mis and behavioral research: Integrating new and existing techniques, MIS Quarterly 35(2): 293-334.

Mahaney, R. C. and Lederer, A. C. (2006). The effect of intrinsic and extrinsic rewards for developers on information systems success, Project Management Journal 37(4): 42- 54.

Malhotra, N., Budhwar, P. and Prowse, P. (2007). Linking rewards to commitment: an empirical investigation of four uk call centers, International Journal of Human Resources manage-

Nisar, Q. A., Ahmad, S., Ahmad, U. and Imran, A. (2014). Exploring relationship among rewards, recognition and em- ment 18(12): 2095-2127.

Murphy, B. (2015). The impact of rewards system on employee performance., School of Administration and Business Management: Dublin Business School.

ployees job satisfaction, Middle-East Journal of Scientific Research 21(9): 1533-1540.

Nnaji-Ihedinmah, N. and Egbunike, F. C. (2015). Effect of rewards on employee performance in organizations: A study of selected commercial banks in awka metropolis, European Journal of Business and Management 7(4): 80-89.

Onashile, A. (2017). Impact of performance appraisal on employee productivity: A case of unilever nigeria plc.

Osabiya, B. J. (2015). The effect of employees' motivation on organisational performance, Journal of Public Administration and Policy Research 7(4): 62-75.

Osibanjo, O. A., Adeniji, A. A., Falola, H. O. and Heirsmac, T. (2014). Compensation packages: A strategic tool for employees' performance and retention, Leonardo Journal of Sciences 25(1): 65-84.

Puwanenthiren, P. (2011). Reward system and its impact on employee motivation in commercial bank of sri lanka plc, Global Journal of Management and Business Research 11(14): 312-333.

Qureshi, M. I., Iftikhar, M., Abbas, S. G., Hassan, U., Khan, K. and Zaman, K. (2013). Relationship between job stress, workload, environment and employees turnover intentions: What we know, what should we know, World Applied Sciences Journal 23(6): 764-770.

Raya, R. L. (2015). What's in it for me? using expectancy theory and climate to explain stakeholder participation, its direction and intensity, International Journal of Project Management 33(1): 3-14.

Rehman, T., Schmidt, W., Trittel, N. and Muller, A. (2010). Performance related pay in german public services, Employee Relations 33(2): 140-158.

Ryan, C. and Pointan, R. (2005). Management learning, performance and reward: Theory and practice revisited, Journal of Management Development 33(4): 342-356.

Samnani, A. and Singh, P. (2014). Performance-enhancing compensation practices and employee productivity: The role of workplace bullying, Human Resource Management Review 24(1): 5-16.

Thomas, K. (2008). Human Resources Management, 7th ed. edn, Edinburgh: Pearson Education Limited.

Thomas, K. (2009). The four intrinsic rewards that drive employee engagement, Global Journal of Management and Business Research 9(6): 101-109.

Yapa, B. (2002). An examination of the relationship among job satisfaction, rewards, and organizational commitment, Journal of the Management Sciences 1(1): 46-66. 